\title{
Pioneering a learning partnership: the University of Texas, SPIE, and the federal government together extend a hand to semiconductor manufacturers
}

Meg Karakekes, Ray Chen

Meg Karakekes, Ray T. Chen, "Pioneering a learning partnership: the University of Texas, SPIE, and the federal government together extend a hand to semiconductor manufacturers," Proc. SPIE 2525, 1995 International Conference on Education in Optics, (13 October 1995); doi: $10.1117 / 12.224039$

Event: SPIE's 1995 International Symposium on Optical Science, Engineering, and Instrumentation, 1995, San Diego, CA, United States 
Pioneering a learning partnership: The University of Texas, SPIE, and the Federal Government together extend a hand to semiconductor manufacturers

Meg Karakekes and Ray Chen

The University of Texas at Austin, Microelectronic Research Center

Austin, Texas 78712

\begin{abstract}
Semiconductors (the process of making computer chips) is the most competitive component of the electronics industry. To stay competitive, semiconductor manufacturers need employees who continually learn. In an industry in which the knowledge base turns over every three years, keeping engineering professionals on the cutting edge is a challenge. This paper specifically examines the first year activity and outcomes of a regionally based pilot program serving the continuing education needs of semiconductor manufacturing engineers. The experimental program's success depends on effective partnering among The University of Texas, The International Society for Optical Engineering (SPIE), the Federal Government, organizations representing displaced engineers, and semiconductor manufacturers in the Southwest.
\end{abstract}

Keywords: Semiconductor, engineering, microelectronics, The University of Texas, SPIE, NSF, evaluation, NAPEM

\title{
2. THE ALLIANCE
}

In 1994, the National Science Foundation (NSF) awarded a Technology Reinvestment Program (TRP) grant to the National Alliance for Photonics Education in Manufacturing (NAPEM). With support from the TRP and matching funds, NAPEM began a 36 month experiment aimed at enhancing national manufacturing through regionally based educational programs focusing on applying photonics in commercial applications. Table 1 identifies the alliance members. SPIE's role is to help to coordinate and promote all the programs. NAPEM's educational programs target displaced defense industry engineers and former members of the armed forces, as well as manufacturing engineers in the commercial and defense sectors.

The NAPEM approach emphasizes industry/academic/society partnership in curriculum development, program design, and outreach to multiple potential audiences (both in companies and unemployed). NAPEM will identify niche industry needs for training to enhance manufacturing effectiveness, develop corresponding courses to those needs, and continuously improve courses through evaluation, feedback and adjustment. ${ }^{1}$

Table 1: Alliance Members and Manufacturing Areas Served

Merbber

University of Central Florida

Industrial Technology Institute (Michtgan)

University of Connecticut

The Unviersity of Texas at Austin

The International Society for Optical Engineering (SPIE)

\section{Manufacturing Area}

Instrumentation and Control Testing

Optical Metrology and Durable Goods

Laser Materials Processing

Senicondistor 


\section{A REGIONALLY BASED PROGRAM FOR THE SEMICONDUCTOR INDUSTRY}

Austin, Texas has been called a second Silicon Valley because of semiconductor related activity in and around the city. The University of Texas at Austin has a new \$31.5M Microelectronics, Material Science, and Engineering Research Building. Sixty percent of the building is devoted to microelectronics research, including clean room space for crystal growth and device processing and characterization lab space. Semiconductor manufacturers in the Austin area include: Advanced Micro Devices, Austin Semiconductor, Cypress Semiconductor, and Motorola. Sematech, a joint venture supported by federal funds and eleven semiconductor manufacturers, is also located in Austin. Sematech's mission is to "Solve the technical challenges required to keep the US number one in the global semiconductor industry. " In addition to Sematech's programs, two annual events draw semiconductor manufacturing engineers to Austin each October -- the SEMICON/Southwest trade show and the Microelectronics Manufacturing Conference.

Within a relatively short distance from Austin are other centers of semiconductor manufacturing activity. Nearby San Antonio, Albuquerque, Phoenix and the Dallas/Ft. Worth Metroplex, are all an easy flight, or even drive, away. And wherever semiconductor manufacturers are well represented, the associated equipment and other support industries are too.

Additionally, with the closing of Bergstrom Airforce Base and the downsizing at local high tech industries (IBM, Lockheed, Tracor) it appeared that Austin would provide a supply of individuals making a career transition to a new industry.

\section{PHASE ONE - - PLANNING}

A 1992 IEEE survey of United States members revealed that engineers perceive the greatest challenges to the profession to be:

1. automation along with the technology and new products needed for managing information

2. the need for effective and continuing education to keep up-to-date. ${ }^{2}$

From NAPEM's perspective these two go hand in hand. Photonics plays a critical role in many areas of automation, and optics will provide significant technology and new product development for future generations of computer chips. Computer chips with optical interconnects will provide that speed in intra and inter - MCM (multichip module) and backplane levels. Additionally the use of optics is increasing across all phases of semiconductor manufacturing. Rogers and Gibson clarify the impact of this second challenge for engineers in the semiconductor industry, "High technology continuously advances at a rate much faster than technology in other industries. . . Certain subindustries within electronics, like semiconductors or microcomputers, are based on a technology that is advancing most rapidly. Microelectronics is therefore the highest of high tech." 3 The researchers observe this; the semiconductor manufacturers experience the impact of this fast rate of change. Gary Heerssen, a Vice President for Advanced Micro Device's manufacturing facilities in Austin, Texas, observes, "Our industry goes through a technological evolution every three to four years. By 1999, the skills and knowledge required to support our manufacturing processes will be far beyond what we have today." 4

To better assess the continuing education needs of semiconductor engineers, the University of Texas at Austin and SPIE recruited a Curriculum Advisory Board (CAB). The CAB included representatives from defense industries (Tracor and E-Systems), semiconductor manufacturing (Advanced Micro Devices and Texas Instruments) and microelectronics related organizations (MCC and IBM). The CAB recommended thirteen well-respected instructors to teach short courses (four to eight hours in length) for the pilot Professional Development in Semiconductor Manufacturing program. The CAB also agreed that the pilot program should be scheduled at the same time as the SEMICON/Southwest trade show and co-located with the Microelectronics Manufacturing Conference. Table 2 identifies the short courses selected for the pilot program.

To meet anticipated participant needs, SPIE arranged for a university-equivalent credit certificate from the University of Texas at Austin's College of Engineering for attendees who completed a series of five courses. SPIE agreed to issue CEUs to attendees who requested them. 
Table 2: Pilot Progam Short Courses

\section{Short Course}

Tithography for Manufacturing

Survey of Optoelectronic Devicest

Optoelectronic Interconnects \& Packaging*

Optical Diagnostic Tectiniques for Plasma Processing

Optical Metlods for Passive Monitoring of Bull \& Surface Propelties

Formation of Scaled Oxides \& Junctions for Deep Sibmicron

Semicondiretor Material \& Device Characterization Issues

Plastic IC Packaging: Issembly \& Reliability Issues

Silicon Defect Enginering Science \& Technology

Advanced Silicon Wafer Cleaning

New Fatiure Mechanisms in Submicron Semiconductor Devices

Process Integration issues in Microelectronic Manufacturing

Relability \& Manufacturing Issues of ULSI Devicest
Instructor(s)

Chris Mack

Joe Campbell

Ray Chen

Gary Selivyn.

John . owell \& V Valene Wenner

Carlton Osbun

Dieter Scliroder

1.11. T. Nguyen

George Rozgonyl

Richard Novak:

Tin Turner:

Badil EL Lareh

Jack Lee

Based on research being condicted at The University of Texas Microelectronics Research Center.

\section{PHASE TWO - THE PILOT PROGRAM}

\subsection{Program Promotion}

SPIE created a brochure that described each course and profiled the instructors. SPIE sent this to all its US members. Also, the direct mail piece for the Microelectronic Manufacturing conference (co-located with the short courses). mentioned the Professional Development in Semiconductor Manufacturing short courses. The Continuing Education Division of the University of Texas at Austin's Engineering Department listed the short courses in its mailing too.

Besides the direct mail efforts, eighteen organizations were targeted for site visits (see Table 3). Eleven agreed to meet with NAPEM representatives. Companies who were not willing to schedule a meeting gave reasons ranging from limited training budgets to an unwillingness to meet with vendors. Veterans Affairs and the Lockheed Outplacement Center did not respond to phone messages. Visiting with industry representatives and professionals managing the transition of defense workers provided opportunities to build relationships and receive feedback. NAPEM offered a group discount to companies sending more than 10 participants. Also, a greatly reduced fee was offered to displaced workers. Additionally, partnering with the Private Industry Council (PIC) enabled NAPEM to reach displaced workers, including those from Lockheed, since PIC had an outplacement services contract with Lockheed.

\section{$\underline{5.2 \text { Course Implementation }}$}

Two hundred twenty-seven incidences of short course attendance occurred. Thirty companies and several universities sponsored attendees. Three displaced workers participated. Forty-eight percent of the registrants came from companies NAPEM representatives had visited. Some attendees were from foreign countries -- Germany, Israel, Taiwan. This international flavor was a benefit of being co-located with the Microelectronic Manufacturing Conference. Across the thirteen short courses, attendance ranged from a high of 40 participants to a low of 3. 
Table 3: Targeted Organizations

Advanced Micro Bevices (A ustin)*

Austin Semiconductor (Austin)

Cypress Semicondictor (Austin Area)

E. Systerns (Dallas R. Worth Metroplex)?

IBM (Austin):

Motorola (Austin)*

Natronal Semiconductor (Dallas/Ft. Worth Metroplex)*

Sernarech (Austin)*

Texas Instruments (Austin)

Veterans Affairs (Austin)
Applied Materials (Austin):

Best IC Labs (Austin)

Dallas Semicondictor (Dallas)*

Hitachi (Dallas Ft. Worth Metroplex)

Lockheed (Austin)

Nationa! Instrinients (Austin)

Private Indistr (Counctl (Austin).

SGS Thompson (Dallas)*

Texas Instruments (Dallas) *

Thaicates NAPEM representatives net with the company s engineering and/or human resources staff:

Participant profile data was requested on the course evaluation form. Less than half the participants provided this information. In the figures below, the " $N$ " for each category represents the total number of respondents. Figure 1 shows the years of experience. Sixty-two percent of the participants had more than five years experience working in semiconductor manufacturing. The respondents who had significantly more than five years of experience did not have a way to report that. The education data indicated that $62 \%$ of the respondents held graduate degrees -- 20 held $\mathrm{PhDs}$. Figure 2 shows the respondents' levels of formal education. Having the short courses co-located with the Microelectronic Manufacturing Conference contributed to the number of participants with doctoral degrees. Since the Curriculum Advisory Board had designed the short courses for semiconductor manufacturing engineers, it was not surprising that $83 \%$ of the respondents classified themselves as Engineers. See Figure 3 for a breakdown by position title. The participation of Maintenace Technicians from local companies was unanticipated, though welcomed.

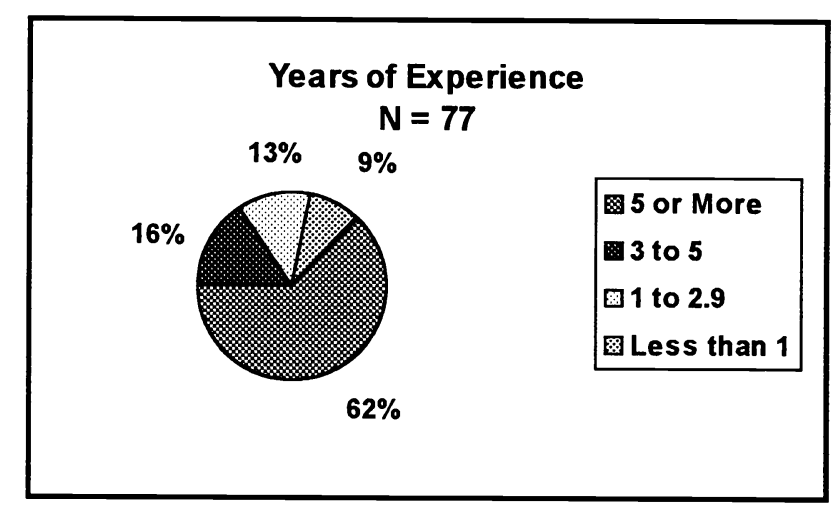

Figure 1

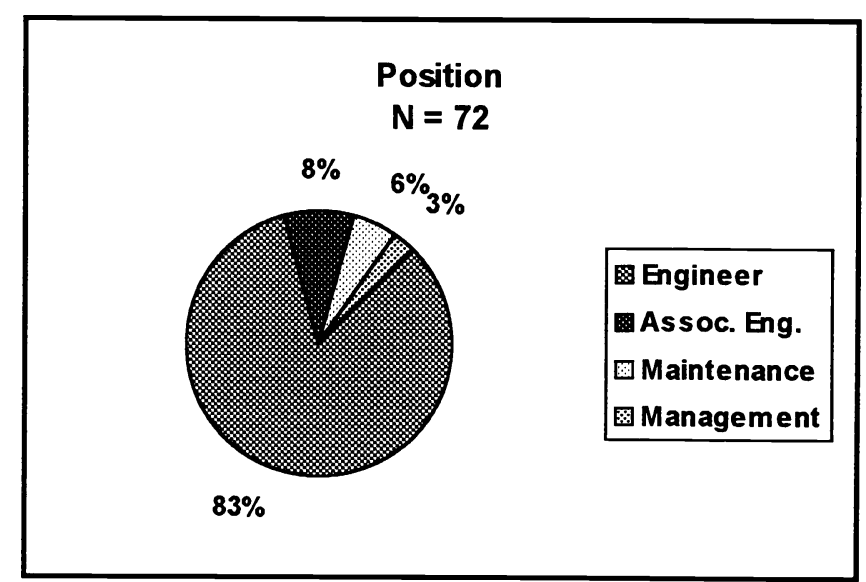

Figure 3 冈ngineer

Assoc. Eng.

Maintenance

图 Management

\section{Formal Education Level $\mathbf{N}=\mathbf{8 3}$}

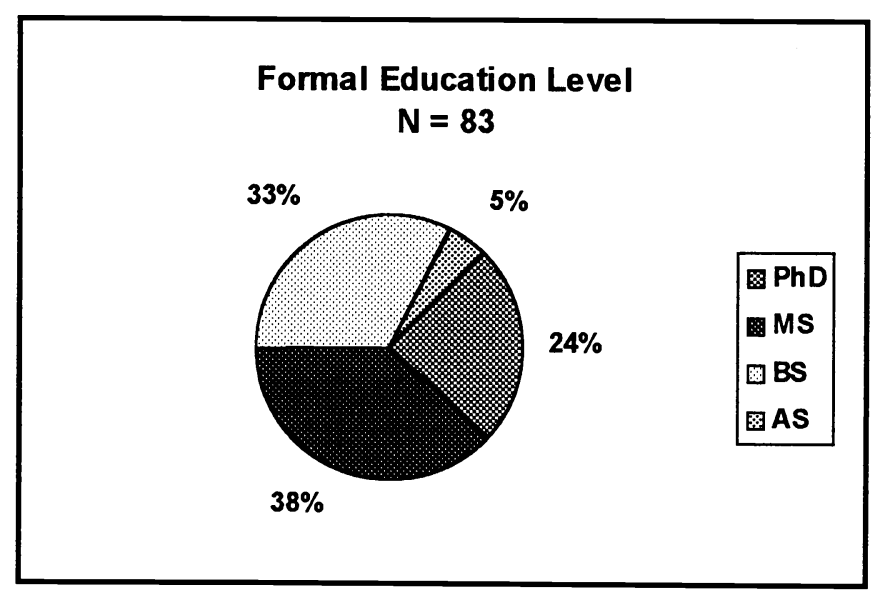

Figure 2

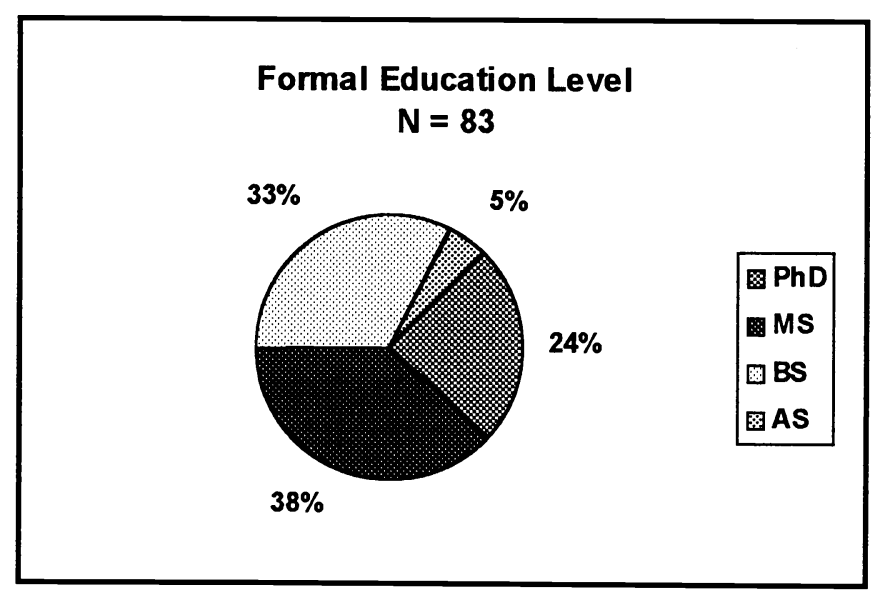




\section{EVALUATION}

Training evaluation has increasingly been a business focus. The American Society of Training and Development's publication, The Best of Evaluation of Training $(1991)^{5}$ identifies that companies increasingly want justification for training dollars. End-of-course evaluations cannot accomplish this alone. In the grant proposal, NAPEM had commited to both endof-course and follow up evaluations. This formative evaluation strategy was designed to enable NAPEM to better serve its partners and enhance future the short course offerings.

\section{$\underline{6.1 \text { End-of-Course Evaluation }}$}

During the eleven short courses not lead by Curriculum Advisory Board members, a representative from The University of Texas or SPIE briefly explained the NAPEM concept, the regional goals, and the importance of feedback on this pilot program. Participants were urged to complete the end-of-course evaluation form and place it in a collection box outside the course meeting room. The evaluation form gave SPIE's address for participants who preferred to mail in their evaluations. The return rate on the end-of-course evaluation form was $49 \%$.

Each person who turned in a course evaluation form answered the course evaluation questions. One question asked the participants to give an overall course rating, using a scale of 1 (low) to 5 (high). When the responses for each course were totaled and averaged, ten courses received ratings between 4 and 5. Participants rated the three remaining courses between 3.76 and 3.96. (For specific course ratings see the Appendix.) Participants also made suggestions about course improvements and future course topics. Two displaced workers said they enjoyed the courses; however, networking with engineers employed in the semiconductor manufacturing industry was the most valuable part of their experience.

\subsection{Follow Up Evaluation}

Evaluation researchers recommend waiting three months after a training event before asking participants how they have applied training. In February of 1995, a follow up survey was sent to short course participants who reside in the United States. Table 4 lists the evaluation questions used.

Table 4: Follow Up Questions

What have you done differently at vork as a result of patticipating in the short course?

What additionat information have you sought as a result of the short course?

Did y ou share whit you learned at the short course with others who then applied the knowledge in the workplace?

In March, follow up phone calls were made to those who had not responded and who had listed phone numbers on their registration forms. Of the 115 participants who were sent surveys, 30 responded (26\%). The respondants were from Advanced Micro Devices, FSI, ILC, NIST, Sematech, Texas Instruments, three universities, and included one displaced worker. Table 5 shows sample data for one short course. ( See the Appendix for more evaluation data.)

Table 5: Follow Up Data for the Optical Diagnostic Techniques in Plasma Processing Short Course.

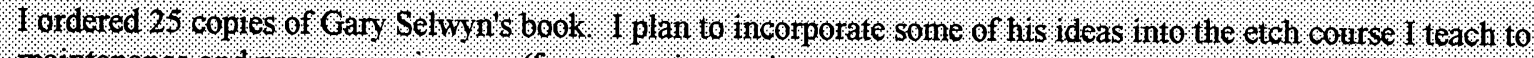
inaintenance and process engineers. (from a senior engineer)

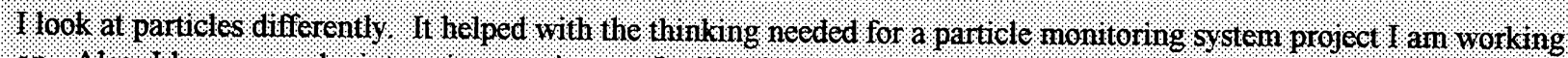
on level engineer

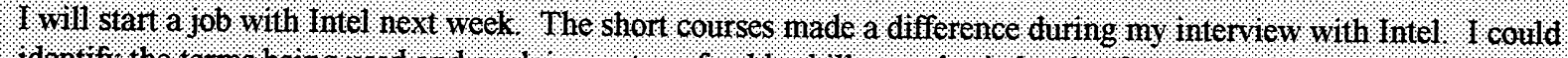
identiff the terms being used and explain ny transferable skills on a basic level. (from a displaced worker) 


\section{OPPORTUNITIES FOR IMPROVEMENT}

\section{$\underline{7.1 \text { End-of-course Evaluations }}$}

The end-of-course evaluations gave valuable suggestions for improving existing courses and for additional course topics. SPIE sent end-of-course evaluation data to each of the instructors. The Curriculum Advisory Board (CAB) used the participant course suggestions to select the short courses for 1995. In 1994, only $49 \%$ of the participants completed end-ofcourse evaluations. Increasing the number of participants who complete end-of-course evaluations is a goal for the upcoming short courses.

\subsection{Dislocated Workers}

Despite efforts to attract dislocated defense workers to the short courses, only three participated. Dislocated workers accounted for twelve short course registrations. Several factors may have accounted for the low dislocated worker turnout:

- Austin's unemployment rate is under $4 \%$

- Dislocated defense workers in Austin may have more interest in computer related engineering rather than manufacturing related engineering. This is true for many of those laid off from Lockheed. Also, the PIC staff reported that while they had dislocated engineers as clients, not many were interested in working in 24-hour a day manufacturing facitilies. Admittedly, in these facilities, new hires often are put on night shifts.

- The short courses were offered four to six weeks after Lockheed and IBM announced layoffs. The severance packages and short period of time between the layoff announcements and the short courses did not allow the dislocated workers to fully explore their options and consider re-careering in the semiconductor industry. One dislocated worker who attended the short courses had received a layoff notice from Lockheed. Three months after the short courses, he was still working full time at Lockheed.

- Dislocated workers from the Dallas/Ft. Worth Metroplex may not find it cost effective to incur travel expenses to come to Austin for courses. Also, a guarantee can not be made that taking a series of courses and networking with employed engineers will result in an interview, let alone a job.

The Project Coordinator for the Dislocated Worker Program at the Private Industry Council has agreed to join the CAB and offer guidance in effectively getting information out to dislocated engineers and technicians.

\subsection{Linking Theory and Application}

Participants in the 1994 program and members of the $C A B$ gave positive feedback about courses in which theory and application were both offered. All short course instructors will continue to identify ways to make this link. Additionally, five courses with "hands on" components will be offered in 1995. The 1995 Optoelectronic Interconnects and Packaging course will take engineers into a research lab for demonstrations of this cutting edge technology. Additionally, three skills-based courses with a significant hands on component will be offered: Basic Fiber Optics, Thin Films and Systems, and Basic Vacuum Techniques.

\subsection{Widening the Target Audience}

Although maintenance technincians were not a targeted population for the 1994 short courses, a nunber of experienced individuals in these positions came and responded favorably to the courses. When the 1995 courses are announced, scientists, engineers, maintenance technicians, and dislocated technical workers will comprise the target audience. 


\section{SUCCESS STORIES}

\subsection{Application in the Workplace}

The follow up surveys revealed that a number of applied what they had learned in the short courses back on their jobs. Courses with the greatest report of transfer back to the workplace were: Optical Diagnostic Techniques, Advanced Silicon Wafer Cleaning, Plastic IC Packaging, Formation of Scaled Oxides and Junctions.

\subsection{Establishing Partnerships}

The industry and PIC site visits made a critical difference. Forty-nine percent of the attendees came from companies to which site visits were made. Also, meeting with engineering managers and human resource development staff was more effective than meeting only with engineering managers. The human resource development staff at the three most well represented companies (Advanced Micro Devices: $23 \%$, Sematech: 11\%, and SGS Thompson $9 \%$ ) were the internal promoters of the Professional Development in Semiconductor Manufacturing short courses. As a result of the site visits, Sematech is now represented on the Curriculum Advisory Board.

\section{$\underline{8.3 \text { Numerical Indicators }}$}

Both the number of registrants and the participant ratings of the courses indicate success. Registration for two courses closed early because the courses were full. Also, no course received a rating below 3.75 on a 5 point scale. Participants rated $77 \%$ of the courses 4 or higher.

\subsection{A Learning Alliance}

The October 1994 semiconductor manufacturing short courses comprised the first regional pilot for NAPEM. The University of Texas and SPIE staff shared what they learned from the pilot at the November 1994 NAPEM meeting. The other members would not pilot their regional programs until 1995, so they could examine what had worked and opportunities for improvement based on the pilot in Texas.

\section{ACKNOWLEDGMENTS}

Susan Anderson, SPIE's Program Manager for NAPEM, offered invaluable encouragement and support during the tougher times of this pilot program. Janna Oddie, Administrative Assistant for the NAPEM project at The University of Texas, contributed significantly to the evaluation follow up with short course participants. Last, but not least, without the Federal TPR grant and the National Since Foundation, this experiment would not have possible.

\section{APPENDIX}

\section{NAPEM/The University of Texas Follow-up Survey \\ Application of Semiconductor Manufacturing Short Courses in the Workplace Summary by Course}

Lithography for Manufacturing

End of course rating for "The content of this course will be useful in my work": $4.47 / 5$

- I have been an engineer in the photo module for several years. This course was too basic for me. I did not learn anything new to apply on the job. I would like to see an advanced version of this course offered. 
- In my job function, I have not utilized the tools learned at the short courses to any degree of significance. I work in part of our Marketing department and am more interested in analysis of the basic technology behind microlithography. We manufacture specialty lighting including Stepper lamps for exposure of photoresist and are trying to better market our products in the semiconductor field. I have only shared broad details of the course with my colleagues.

- In my environment and position I do not physically do lithography. NIST influences lithographic processes by the development of standards. This was more for information purposes. Yes, I have shared what I learned with others as questions arose.

- As a result of the Lithography for Manufacturing short course, I have a better understanding of resist chemistry. This knowledge is important to my job since I evaluate experimental resists. This course gave me the basics for a more indepth course I took recently (Resist for Deep-UV Photolithography). I did have the opportunity to share some of the information on EO swing curves with a manufacturing technician who was assisting me with a swing curve experiment.

- Our Applications Lab has been shut down since I took the Lithography for Manufacturing course. I enjoyed the course, but I have not been in a situation yet where I used any of the information taught. The need for a refresher course may be in order. Once we have our lab functional again, I will be looking a taking more short courses.

- I used some of the material to setup an hour long outline of how lithography works at my company.

- Chris Mack is a good teacher and a good engineer. His short course helped me understand all the tools available in the market. We may consider using them if needed. Send me a list of future short courses.

Optical Diagnostic Techniques for Plasma Processing 8 Participants 8 completed end of course evaluations End of course rating for "The content of this course will be useful in my work": $4.38 / 5$

- I ordered 25 copies of Gary Selwyn's book. I plan to incorporate some of his ideas into the etch course I teach to maintenance and process engineers.

- I look at particles differently. It helped with the thinking needed for a particle monitoring system project I am working on. Also, I have an endpoint project coming up; I will refer back to the course materials for that project.

Semiconductor Material and Device Characterization 32 Participants 14 completed end of course evaluations End of course rating for "The content of this course will be useful in my work": 4.29/5

- I can't point specifically at what I've done differently, but I can tell you that my understanding of these physics problems is greater. I have most likely used that knowledge in understanding electrical test or simulation results. The course was definitely worthwhile for me.

- I was called out of that particular class to come back to work so the answer is no. I have made use of information from the other short courses I took.

- This short course helped me understand the tools available on the market. I shared the information with others.

Process Integration Issues

40 Participants 23 completed end of course evaluations

End of course rating for "The content of this course will be useful in my work": $3.77 / 5$

- I have been slightly better able to converse with counterparts in various other semiconductor processing areas as a result of learning from this course. I have sought to learn more about Process Integration, particularly as it relates to Design and Characterization. I have shared some of the learning with others, though I am not certain if this has helped them substantially with their duties.

- The NAPEM course was a valuable overview of current integration technology, given that my last official schooling was in 1986 and I have been focused on a particular technology (lithography) for the past 8 years. I have applied the classroom knowledge to analysis of factory production flows since the course. The class met all of my desired needs. 
- The course in Silicon Defect Engineering was good information for future reference involving defect analysis/evaluation. However, Product Engineers would receive the greatest benefit from this class.

- After the class, I re-aligned the inspection microscope per the instruction in the class and fanned out what I learned to my engineers and technicians.

\section{Advanced Silicon Wafer Cleaning}

26 Participants 18 completed end of course evaluations

End of course rating for "The content of this course will be useful in my work": $4.5 / 5$

- While attending the class I had the opportunity to speak with the instructor regarding ozonated sulfuric acid cleans. Based on that discussion, my fab decided to modify a sink so it could run a sulfuric/hydrogen peroxide process which is supplied by the bulk acid delivery system.

- We are testing the standard clean two bath without $\mathrm{H}_{2} \mathrm{O}_{2}$. This was one of the ideas mentioned in the short course.

- This class gave me a better understanding of the latest wafer cleaning techniques. One of my engineers has an ERF to apply one of the techniques. After the class my discussions with him may have helped to speed the experiment.

- I have used the information obtained to better understand the wet process cleaning as I have had no experience to what was involved with this process technology.

\section{Scaled Oxides \& Junctions for Deep SubMicron 19 Participants 15 completed end of course evaluations}

End of course rating for "The content of this course will be useful in my work": 4.13/5

- I have been working for the past three years on thin oxidation, so that part of the course was a refresher more than anything else. As far as the implant section is concerned, it did teach me a number of things I was previously unaware of, and I have utilized some of the topics in my work.

- I have not applied the information directly in my job, mainly because most of the course covered fab-related issues. The course though, helped me understand the problems of scaling the oxide which is an important issue for VLSI product engineers.

- I took this course to anticipate issues that our group may be facing over the next several years. I am currently working in the process engineering group of a wafer fab that builds mixed signal ICs with minimum feature sizes ranging from 1.0 micron up to 5.0 micron. The issues covered in this short course dealt primarily with technologies where the minimum feature size was less that 0.5 micron. Despite the fact that I will not be able to directly apply the information learned in this short course to my current work, I found the course very informative and worth the time and money invested. I will recommend the course to others in our engineering group as a good forum for addressing future issues that we will ultimately face. Perhaps the most important message carried from the class was the changes in processes and equipment that will be required to move to smaller feature sizes.

\section{Plastic IC Packaging: Assembly and Reliability Issues 16 Participants 14 completed end of course evaluations}

End of course rating for "The content of this course will be useful in my work": $4.29 / 5$

- The difference this course made for me was to increase my confidence level in (a) dispositioning non-conforming product in fab, (b) guiding fab process changes, and (c) determining appropriate process and product qualification requirements. This is because I feel I now have an increased awareness, if not understanding of how "the other side works."

- It (the course) has given me some insight into potential yield issues caused by package stress. This is helpful knowledge for me to have when I am dealing with the product lines. 
- As a student, my major interest was in determining whether there were any problems seen in practice that had not been already covered in the courses I've attended at school. From this perspective, I did not learn anything new. However, the insight provided by the instructor on the actual process by which certain problems were identified and resolved was extremely valuable. A useful complement to the course would have been the provision of a brief set of notes, annotating the diagrams supplied in the instruction booklet -- this would allow more time to concentrate on the ideas being presented.

- The notes provided were terrible (only one or two sentences per page). There were no references of legible figures. Even with all the above, the notes were the thinnest I ever got in a course. I do not believe I benefited from this course. I do some reliability work on devices and hoped to learn more, get an overview, and a survey type documented short course. The only way one could have learned something was by bringing with him/her a video camera. I actually raised the issue about references and the instructor promised to provide us with some, but nothing has materialized so far (four months later). My conclusion is that even though the speaker knew his subject, the materials he provided were not helpful. Maybe as a private consultant, he did not like to have his knowledge shared through notes. If NAPEM is to continue offering courses in such a style, it is doing a great injustice to those registering for the courses.

Reliability and Manufacturing Issues of ULSI Devices 27 Participants 11 completed end of course evaluations End of course rating for "The content of this course will be useful in my work": 3.82/5

- This short course emphasized device modeling rather than starting with an overview of reliability and possible failures. Many people, including me, felt that way. I only attended the first two hours of the short course. The notes were good and I used parts of it in teaching my undergraduate classes. The instructor could have started by reviewing the failures mechanisms and reliability and the manufacturing issues, physical origins, and then as he goes along could have used the necessary models when needed.

\section{A Four Short Course Series}

- I will start a job with Intel next week. The short courses made a difference during my interview with Intel. I could identify the terms being used and explain my transferable skills on a basic level.

\section{FOOTNOTES/REFERENCES}

${ }^{1}$ NAPEM Executive Summary, 3 Nov. 94, p. 3.

${ }^{2}$ H. Wolff, "How Engineers View Themselves" IEEE Spectrum, April 1993, pp 24 - 28. actually used 28

${ }^{3}$ M. Rogers and D. Gibson, "Technology Transfer in High-Technology Industries" Technology Companies \&

Global Markets, Edited by David V. Gibson, p. 41, Rowman \& Littlefield Publishers, Savage Maryland, 1991.

${ }^{4}$ G. McDaniel, and M. Karakekes, "A Model for Designing Organizational Learning," Proceedings, The Tenth

Annual Texas Conference on Organizations, p. 93. Lago Vista, TX, 1995.

${ }^{5}$ ASTD, The Best of Evaluation of Training, Alexandria, VA, 1991 